\title{
LA SEMIÓTICA DE LA TRADUCCIÓN AUDIOVISUAL PARA INVIDENTES
}

\section{Ana Isabel HERNÁNDEZ BARTOLOMÉ Gustavo MENDILUCE CABRERA ${ }^{1}$}

\author{
Universidad de Valladolid \\ aihb@fyl.uva.es \\ gustavom@itbyte.uva.es
}

\begin{abstract}
Resumen: La audiodescripción es una nueva modalidad de traducción audiovisual que facilita la comunicación de las obras de cine y teatro a los invidentes. En el artículo presentamos su complejo entramado semiótico, proceso técnico, aplicaciones e historia en España.
\end{abstract}

Abstract: Audio description is a new type of audiovisual translation that makes film and theatre communication easier for the blind. This paper offers an overview of the complex semiotic network, technical process, applications and Spanish history.

Palabras clave: audiodescripción, traducción audiovisual, semiótica, discapacitados, invidentes, Audesc.

Keywords: audio description, audiovisual translation, semiotics, disabled people, visually impaired, Audesc.

\footnotetext{
${ }^{1}$ Becarios FPU de la Secretaría de Estado de Educación y Universidades (MECD).
} 


\section{PRESENTACIÓN}

En este artículo nos adentraremos en el campo de la traducción audiovisual (TAV), área relativamente reciente dentro de los Estudios de Traducción. A pesar de su corta existencia, este tipo de traducción abarca un variado abanico de productos de masas. No obstante, nos ocuparemos de la traducción para un colectivo minoritario, como es el de los deficientes sensoriales, cuyas necesidades específicas apenas han sido estudiadas en el ámbito académico. Más concretamente, analizaremos la audiodescripción (AD) para ciegos, un sistema en el que intervienen múltiples y complejas relaciones semióticas. En este trabajo presentaremos el sistema Audesc, una experiencia intersemiótica impulsada por la Organización Nacional de Ciegos Españoles (ONCE), que aplica la AD para facilitar el acceso de productos audiovisuales a invidentes y deficientes visuales.

\section{LA AUDIODESCRIPCIÓN DENTRO DE LA TRADUCCIÓN AUDIOVISUAL}

En la actualidad, y desde hace un par de décadas, los estudios de TAV están viviendo un momento dulce, que algunos han calificado de eclosión (Chaume Varela, 2002: 215). Somos testigos de un gran incremento de la investigación en este campo, como se manifiesta en el creciente volumen de tesis doctorales, artículos, congresos, actas... que abordan este tema. Sin embargo, por curioso que pueda parecer, la mayoría de los trabajos se ha centrado en unos pocos enfoques - especialmente, el proceso traductor- mientras que otros muchos siguen aún vírgenes (Bravo Gozalo, 2002: 188). Uno de ellos, considerado, además, por los estudiosos una de las líneas emergentes (Bravo Gozalo, 2003; Chaume Varela, 2002), es la TAV para colectivos discapacitados. Aunque poco numerosos, no faltan trabajos que han apuntado la importancia de la subtitulación para sordos (Mayoral Asensio, 2001; Linde \& Kay, 1999). Por el contrario, las necesidades de los deficientes visuales han recibido una atención mínima en la literatura, reduciéndose a meras menciones en el mejor de los casos (Bravo Gozalo, 2003; Chaume Varela, 2002). De hecho, no conocemos ningún trabajo que 
hasta la fecha se haya ocupado de este fenómeno, a pesar de que, paradójicamente, todos reconocen su importancia. Es por ello por lo que en este artículo pretendemos aportar nuestro granito de arena en la fase inicial de esta investigación, centrándonos en el fenómeno de la AD de ayuda al colectivo invidente, y en particular en Audesc, el sistema audiodescriptivo adoptado en nuestro país.

\section{LAS RELACIONES SEMIÓTICAS EN LA AUDIODESCRIPCIÓN}

La $\mathrm{AD}$ es el comentario insertado en los silencios de películas, obras de teatro y programas de televisión cuya misión es describir las imágenes relacionadas con el escenario, el atrezo, el vestuario, las expresiones faciales, el lenguaje corporal, la acción, etc. a todas aquellas personas que tengan graves problemas de visión (Silverwood, 1992: 10). La finalidad del sistema es aportar información relevante para que los deficientes visuales sean capaces de disfrutar de los productos audiovisuales del modo más similar posible al de cualquier vidente. Por lo tanto, podemos afirmar que la $\mathrm{AD}$ es el arte de traducir imágenes en palabras.

\subsection{Los componentes semióticos en las artes audiovisuales}

Los textos audiovisuales son muy heterogéneos desde el punto de vista semiótico por componerse de variados elementos conjugados para dar lugar a un valor significativo único. Habitualmente se considera que todo producto audiovisual emite su contenido a través de dos canales: el acústico y el visual, que mantienen una coordinación comúnmente conocida como sincronización. Pero la complejidad semiótica va más allá, al transmitir estos dos canales diferentes tipos de códigos, como son el código verbal, el código literario y teatral (argumento, estrategias narrativas, diálogos, etc.), el código de conducta no verbal (integrado por elementos proxémicos, kinésicos, morales, etc.), el código cinemático (técnicas, géneros, etc.) (Delabastita, 1989: 196-197). Esta diversidad de elementos convierte al producto audiovisual en un macrosigno en el cual confluyen numerosos códigos que aportan información, combinados para formar una unidad significativa cohesiva. Precisamente, esta 
multiplicidad de códigos es la que hace posible que tenga sentido realizar la AD. Si el cine solo dependiese de imágenes y diálogos, sería impensable que una persona ciega fuera capaz de seguir una película audiodescrita.

A esta complejidad hemos de añadir el juego semiótico de interpretaciones, de modo que un mismo producto será interpretado desde múltiples puntos de vista, dependiendo del trasfondo sociocultural y la capacidad de decodificación de cada receptor. De este modo, la comunicación ha de ser concebida como bidireccional e interactiva (Bastos Duarte, 2001: 155).

\subsection{Los diferentes tipos de traducción en la audiodescripción}

El hecho de que la $\mathrm{AD}$ trasvase el componente icónico al verbal tiene connotaciones semióticas muy importantes. El macrosigno audiovisual pierde uno de sus canales y necesita que esa información se transmita a través de otro medio para no alterar su valor semiótico significativo. Para comprender mejor esta traslación semiótica, recurriremos al concepto de traducción propuesto por Roman Jakobson $(1971 \mathrm{a})^{2}$. De este modo, los procesos que tienen lugar en la AD son:

- La traducción interlingüística, entendida como «una interpretación de los signos verbales mediante cualquier otra lengua» (Jakobson, 1971a: 261). Como consecuencia del predominio del cine de Hollywood en nuestro país ${ }^{3}$, la gran mayoría de las películas que consumimos están en lengua inglesa, por lo que han de pasar por las manos de los traductores audiovisuales convencionales para que se produzca el primer paso del trasvase necesario para la AD. En el resto de las artes audiovisuales, el porcentaje es menor; no obstante, la necesidad de traducción de una lengua a otra sigue siendo muy elevada.

2 Somos conscientes de que existen clasificaciones posteriores, como las de Gideon Toury (1986) y Umberto Eco (2001), pero preferimos basarnos en la clásica de Roman Jakobson, origen de las anteriores.

3 En 2002, la cuota de pantalla del cine español fue del 13,6\%, mientras que la del cine americano alcanzó el 70\% (AAVV, 2003: 8). A finales de 2003, la recaudación de las películas estadounidenses cuatriplicaba a las españolas (AAVV, 2004: 11). 
- La traducción intersemiótica o transmutación como «interpretación de los signos verbales mediante signos de sistemas no verbales» (Jakobson, 1971a: 261). En palabras de Peeter Torop (1995: 40-41) es la traducción «de un tipo de arte a otro (de la literatura al cine o al teatro, etc.), es decir, el texto se saca de sí mismo». Pese a que Jakobson en un principio concibe este tipo de traducción en un solo sentido, más adelante se ampliará el concepto en sentido bidireccional (1971b: 330), con el sentido de la transmutación de un sistema de signos a otro. El trasvase de la literatura a la gran pantalla es considerado como la traducción intersemiótica por antonomasia. No obstante, éste no es el único trasvase posible, puesto que es habitual encontrar transmutaciones en las artes musicales e incluso la danza (Osimo, 2001). Una vez que la obra audiovisual está en la lengua meta —en nuestro caso, en español—, el audiodescriptor trasvasa el contenido icónico de la obra al nuevo sistema verbal, para que, de este modo, los deficientes visuales no se pierdan gran parte del contenido semántico de la obra. De este modo, toda aquella información que se transmita a través de las imágenes, los gestos, los colores, etc., es decir, toda connotación no articulada por medio de palabras, música o sonidos, será vertida oralmente de alguna manera. El texto meta más habitual suele tener forma de narración, de forma que el producto final alterna periodos narrados con diálogos, dando una sensación de cohesión indispensable para el buen funcionamiento de la AD.

- Llegados a este punto debemos destacar que en algunos casos la transmutación va acompañada de la traducción intralingüística o reformulación, que es «una interpretación de signos verbales mediante otros signos de la misma lengua» (Jakobson, 1971a: 261). En el caso de la AD, la traducción intralingüística tiene lugar después de la traducción intersemiótica, cuando el audiodescriptor ha de explicitar cierto tipo de información, como pueden ser explicaciones o comentarios adicionales que faciliten la comprensión del receptor. Aunque este hecho no suele ser habitual, se practica en los casos en que la recepción del producto puede quedar suspendida por falta de detalles claves para el entendimiento del invidente. Por ejemplo, en El espíritu de la colmena aparece una foto que inicialmente se describió como «en la cómoda hay una foto en la que aparece 
su abuelo». No obstante, dicha foto mostraba la imagen del famoso escritor Miguel de Unamuno, por lo que la AD hubo de corregirse para plasmar el detalle (Navarrete Moreno, 1997b: 72). Es decir, la AD no permite la generalización de los detalles, puesto que uno de sus objetivos es fomentar la cultura entre los invidentes.

Por lo tanto, el caso de la $\mathrm{AD}$ es extremadamente interesante desde el punto de vista traductológico. En el proceso audiodescriptivo es muy frecuente encontrar conjugados los tres tipos de trasvase: el interlingüístico, para la comprensión de la obra en la lengua meta, el intersemiótico, para llegar al público invidente, y el intralingüístico, para explicar algún detalle al público invidente.

\subsection{La importancia de la traducción intersemiótica en la audiodescripción}

Cuando uno de los dos textos que integran el proceso traductor es de carácter no verbal —en nuestro caso, el valor icónico del texto fílmico-, el traductor ha de ser meticuloso y tener un criterio claro para seleccionar las partes que se trasvasan y las que no, al tiempo que decantarse por cualquier unidad de las dualidades denotación/connotación, acción/descripción, expresión/contenido, etc. La imposibilidad de diferenciar los signos en el lenguaje icónico dificulta la traducción de las acciones al lenguaje verbal, en el que los signos están claramente diferenciados. Como en toda traducción, siempre ha de haber algún tipo de pérdida, pero en este caso el traductor ha de ser especialmente meticuloso para mantener la coherencia y cohesión esenciales del texto (Osimo, 2001).

Como ya hemos visto en el apartado 3.1, las estructuras semióticas que intervienen en la comunicación audiovisual son extremadamente complejas. No obstante, para lograr un trasvase intersemiótico de dichas formas hemos de buscar algún tipo de equivalencia. Dicha equivalencia se consigue por medio de la homologación ${ }^{4}$, de manera que el autor tenga libertad para seleccionar uno u otro repertorio creativo sin alterar por ello el sentido fundamental de la superestructura, que es la obra audiovisual

${ }^{4}$ Esta homologación es lo que Greimas y Courtès (1982: 209) definen como la «operación de análisis semántico, aplicable a todos los dominios semióticos y que participa del procedimiento general de la estructuración». 
(García Templado, 1997: 260).

Esta traducción ha de procurar no trastocar el ritmo propio de la obra audiovisual. Toda obra audiovisual transmite el ritmo por medio de tres componentes clave: la banda sonora (la música, la voz humana y los ruidos), la narración y el montaje. Si bien la AD pierde el ritmo transmitido mediante los componentes visuales — parte de la banda sonora y el montaje-, el resultado audiodescrito ha de compensarlo a través del ritmo verbal — presente en la voz humana de la banda sonora y la narración (Núñez Ramos, 1995: 188-197). El complejo ritmo audiovisual transmitido mediante unidades compuestas y elementos poco homogéneos ha de traducirse en un ritmo más tradicional, por medio de la emisión de unidades fónicas elementales. De este modo, el efecto de recepción pretenderá ser lo más similar posible al de la recepción del público con capacidad visual.

\section{AUDESC, EL SISTEMA ESPAÑOL}

Descrito ya el entramado teórico subyacente a la $\mathrm{AD}$ desde el punto de vista lingüístico, que aúna semiótica y traducción, pasaremos ahora a ofrecer la realidad pragmática de la $\mathrm{AD}$, es decir, cómo se lleva a la práctica ese complejo proceso. Tras una breve contextualización, nos centraremos en Audesc, la experiencia española de la $\mathrm{AD}$.

\subsection{Contexto de aparición}

Aunque en España la $\mathrm{AD}$ aún no goza de una amplia difusión, sus orígenes se remontan a principios de la década de 1980. Este sistema de traducción intersemiótica apareció por primera vez en los Estados Unidos en 1981 aplicado al teatro. Posteriormente se extendería al ámbito cinematográfico y televisivo, donde curiosamente España fue pionera en el mundo occidental gracias a la experiencia piloto de la cadena catalana TV3 (ITC, 2000: 3). Sin embargo, serían los EEUU, Inglaterra y Francia - con los sistemas de Audio Vision y Mopix, Audetel, y Audiovision, respectivamente - los países que impulsarían la $\mathrm{AD}$, gracias en parte al apoyo gubernamental (Navarrete Moreno, 1997b: 70). 
Centrándonos en nuestro país, el primer intento oficial surgió en 1987 con el proyecto Sonocine, propuesto por Miguel Hidalgo dos años antes (Cejudo, 1991: 28). No obstante, no será hasta 1994 cuando aparezca el sistema Audesc, un nuevo proyecto de la ONCE con perspectivas mucho más ambiciosas. La promoción del sistema por parte de la ONCE ha derivado en que éste sea el sistema exclusivo de AD aplicado en España. Audesc pretende abarcar todas las artes audiovisuales y hacerlas accesibles a los ciegos españoles. Hasta el momento, su principal campo de acción ha sido el ámbito doméstico, mediante la creación de un servicio de préstamo de vídeos a todos los afiliados de la ONCE. Desde el punto de vista comercial, Audesc ha despuntado en el teatro y en el cine. Este salto cualitativo y cuantitativo responde a la función integradora con que nació dicho sistema; de otro modo, los invidentes no tendrían la oportunidad de compartir con sus familias y amigos las obras teatrales y cinematográficas —como venía siendo habitual hasta la aparición de Audesc - relegándolos a la soledad que tradicionalmente ha acompañado a las minusvalías, en este caso, a la ceguera (González e Iorfida, 2002).

\subsection{El proceso de la audiodescripción}

La $\mathrm{AD}$ conlleva un proceso complejo en el que entran en juego diversos profesionales, de los cuales destacan dos figuras clave: el audiodescriptor y el narrador. El audiodescriptor es la persona encargada de trasvasar el contenido de las imágenes en palabras, ya sea en directo o en diferido. El narrador, por su parte, es la persona encargada de leer dichas descripciones (Clark, 2001).

El proceso completo de $\mathrm{AD}$ - para una película de dificultad y duración media - abarca una semana y media de trabajo, aproximadamente. Basándonos en Navarrete Moreno (1997b: 71-74) e ITC (Independent Television Committee) (2000: 711), pasamos a continuación a describir los pasos que componen la $\mathrm{AD}$, es decir, cómo se realiza técnicamente el trasvase semiótico, anteriormente descrito:

a) Selección de las películas. Cada año la ONCE decide las obras que pueden ser de interés, teniendo en cuenta la opinión de expertos y afiliados. No todas las obras son adecuadas para la $\mathrm{AD}$, puesto que no reúnen los 
requisitos mínimos de imagen y sonido — tanto en calidad como en tiempo-

b) Visionado. El descriptor debe captar el espíritu de la obra por lo que se refiere al género, estilo, trama argumental, etc. Asimismo, debe prestar especial atención a los puntos que pueden ser problemáticos en el trasvase de imágenes al guión audiodescrito. Previo a este paso ha debido tener lugar la traducción interlingüística, para que el texto esté en la lengua del público receptor.

c) Elaboración del guión. Es el momento en que el que se produce la traducción intersemiótica: el descriptor decide qué imágenes debe verbalizar y cuáles no, teniendo cuidado de no excluir elementos esenciales ni incluir valoraciones personales. Sin embargo, esto no quiere decir que se haya de privar a los invidentes de una caracterización tanto física como psicológica de los personajes. En este punto también puede darse la traducción intralingüística, en el caso de que esta fuese necesaria. Sin embargo, el concepto de homologación ha de primar por encima de todo tipo de trasvase.

d) Sincronización de la AD. Una adecuada inserción temporal de la narración con respecto a la imagen en pantalla evitará el solapamiento de la $\mathrm{AD}$ con los diálogos originales de los personajes, al tiempo que el excesivo adelanto o atraso con respecto a la acción. Lo ideal sería la sincronía total de imagen y sonido, utopía pocas veces factible, por lo que en términos prácticos la AD se adelanta unos 2 segundos a la pantalla. No obstante, el ritmo de la obra audiovisual no debe ser alterado.

e) Ensayo. La narración ha de expresar los sentimientos que la película despierta en un espectador vidente. De ahí la importancia de la voz del narrador, normalmente elegido entre los actores de doblaje, más acostumbrados a trabajar con tomas y a integrar su voz en la obra.

f) Grabación. En este complejo proceso tecnológico se revisa la calidad de la banda sonora original, se ecualizan las voces y se ajusta cada uno de los cortes audiodescritos con el tiempo y los niveles de sonido de la obra. Una película de cine media tiene entre 400 y 500 cortes y tarda en grabarse entre 4 y 5 horas. 
g) Revisión de la grabación. Se corrigen los errores y omisiones para evitar posibles imperfecciones en la emisión de la AD. Asimismo, se comprueba que se han mantenido todos los criterios intersemióticos para no alterar el valor estético de la obra audiovisual.

h) Distribución de la obra. Los productos emitidos en directo tienen una duración muy limitada, pero los grabados se distribuyen a tra vés de las sucursales de la ONCE. Cada cinta de vídeo cuenta con el título en Braille, los datos de la película y una breve sinopsis.

Tras las relaciones de traducción expuestas en el apartado 3.2, en este artículo proponemos que la figura del audiodescriptor se funda con la del traductor audiovisual. Mientras que el primero es el encargado de la traducción intersemiótica e intralingüística (si ésta fuese necesaria), el segundo se encarga de la traducción interlingüística. No obstante, el proceso de la $\mathrm{AD}$ coincide en muchos puntos con el de dicho traductor audiovisual —visionado, elaboración de un guión sincronizado, conocimiento profundo de la obra, estilo, tono, diálogos, etc.- , por lo que se podría ahorrar mucho tiempo en el proceso. Asimismo, la figura del narrador podría ser desarrollada por los actores de doblaje, habituados ya a trabajar con tomas y a integrar su voz en los productos audiovisuales. De este modo, el sistema Audesc podría ampliar sus horizontes y difundirse de manera exponencial: la mayoría de las obras se traducen antes de comercializarlas y la versión habitual y la audiodescrita podrían ver la luz simultáneamente, con la consiguiente reducción de costes y tiempo.

\subsection{Campos de aplicación}

Caracterizada la $\mathrm{AD}$ desde el punto de vista lingüístico y técnico, cabe preguntarse qué aplicaciones concretas tiene en los productos audiovisuales y cuál es la acogida por parte del público. A estos dos interrogantes trataremos de dar respuesta en las siguientes secciones. 


\subsubsection{Cine}

A lo largo de estos diez años, Audesc-cine ha pasado de las 5 primeras películas adaptadas en 1994 a las 220 disponibles a finales de 2003: un espectacular crecimiento debidamente respaldado por la audiencia. El objetivo integrador al que nos referíamos anteriormente queda reflejado en la amplia gama de géneros, épocas y estilos que engloban el catálogo en la actualidad. Buenos ejemplos son las cinco primeras películas audiodescritas: Belle époque, Casablanca, Instinto básico, Solo en casa y Tacones lejanos, que ya abarcan desde el cine familiar a la producción nacional más actual, pasando por los clásicos (Galisteo, 1994: 5). El repunte que está experimentando hoy en día la proyección de películas en salas comerciales se manifiesta en el reciente interés de importantes festivales de cine, como la Semana Internacional de Cine de Valladolid (SEMINCI) o el Festival de Cine Iberoamericano de Huelva, cuyas dos últimas ediciones han incluido películas audiodescritas (García Mateache, 2003: 13). Estas iniciativas han recibido una calurosa acogida por parte del colectivo de invidentes, hecho que parece haber despertado la conciencia de la sociedad. Como consecuencia, la ONCE está promoviendo la existencia de un servicio habitual de AD en las salas de cine comerciales. Como comenta Ignacio Escanero, Director de Cultura y Deporte de esta institución, «El despegue se ha producido a través de contactos con la Academia de Cine, las administraciones, los festivales o la Escuela de Cine, para que todos ellos se sensibilicen con nuestro problema y se nos facilite el acceso a las salas» (Villaécija, 2002). Los cálculos parecen apuntar al bajo coste de la infraestructura, estimando que 12.000 euros serían suficientes para dotar cada sala comercial con el equipamiento necesario. Dicha cantidad se rentabilizaría en 40 proyecciones con una asistencia de unos 20 invidentes, cifras que, en principio, resultan asequibles. Parece, pues, que los 63.000 afiliados pronto podrán disfrutar del séptimo arte de manera colectiva.

\subsubsection{Teatro}

El panorama de Audesc en el mundo teatral es aún más esperanzador que el del cine. El sistema se presentó en Madrid el 4 de noviembre de 1994 y comenzó a funcionar a los dos días durante la representación de Los mal casados de Valencia en el Teatro Príncipe de la capital de España (AAVV, 1994: 60). Si bien al principio las 
representaciones eran básicamente esporádicas, en la actualidad existen diversos puntos de la geografía española dotados de salas que regularmente presentan obras audiodescritas. A este respecto resulta ineludible mencionar el acuerdo al que llegaron la ONCE y Instituto Nacional de las Artes Escénicas y la Música (INAEM) en octubre de 2001, en virtud del cual Audesc-teatro «se instalará de forma permanente en los teatros nacionales dependientes del INAEM: teatro de La Comedia, sede de la Compañía Nacional de Teatro Clásico, Teatro de La Zarzuela y Teatro María Guerrero, sede del Centro Dramático Nacional» (INAEM, 2001).

\subsubsection{Otros campos de aplicación}

En comparación con otros países, el desarrollo de la $\mathrm{AD}$ en la televisión española es ciertamente limitado. La difusión de documentales, pese a su dificultad intrínseca, es mayor que la de programas en directo. De hecho, el catálogo de la ONCE cuenta con 14 cintas documentales de variado contenido (naturaleza, historia, geografía, etc.). Las excepciones a esta tendencia son TVE1, Canal Sur y Mundovisión. El primer canal ha difundido una serie de dibujos animados (Nicolás) y algunos filmes. El segundo puso en marcha la AD de películas el 5 de marzo de 1995 con el filme Atmósfera Cero, y desde entonces ha continuado con este servicio que semanalmente sincroniza sus canales televisivo y radiofónico. Por otro lado, Mundovisión, cuyo promotor fue el propio Miguel Hidalgo, también desde hace varios años emite programas audiodescritos en directo (Mayoral, 1995: 63). Por lo que se refiere a la televisión digital, la ONCE está manteniendo conversaciones con diversas plataformas para ampliar la cobertura de Audesc, tal como ha hecho recientemente el Canal británico Five (Sky, 2003).

Futuros proyectos incluyen la incorporación de $\mathrm{AD}$ a las visitas guiadas a museos. Sin embargo, dicha iniciativa no verá la luz a corto plazo, así que, por el momento, cada museo adopta medidas dentro de sus posibilidades, como el Museo Nacional de Escultura de Valladolid. Interesante es también la futura AD de páginas web y la incorporación al sistema DVD, hoy día ya una realidad, pese a los problemas técnicos que ralentizan su difusión. 


\section{CONSIDERACIONES FINALES}

Para que la exposición de esta experiencia intersemiótica audiovisual no se quede en una mera colección de anécdotas y datos técnicos o disquisiciones teóricas, queremos concluir presentando una serie de reflexiones.

Por el momento, todos los indicios de que disponemos - las escasas referencias académicas, la gran acogida del público y la progresiva difusión del sistema- apuntan a que pronto la $\mathrm{AD}$ en España tendrá una mayor importancia, quizá equiparable al nivel de los Estados Unidos o Gran Bretaña. Dejará, por tanto, de ser considerada una forma menor de traducción intersemiótica. Si poco a poco la adaptación de obras literarias al cine o al teatro ha ido ganando terreno hasta convertirse en una práctica habitual, no vemos óbice para que no suceda lo mismo con la adaptación de productos audiovisuales para invidentes.

Tampoco debemos olvidar el enorme mercado que hay detrás de la industria audiovisual, lo que, además de ser un aval para la profesionalización de la $\mathrm{AD}$, trae como consecuencia la aparición de nuevas necesidades laborales. En otras palabras, sería necesario formar profesionales preparados para la AD. Por este motivo, reiteramos nuestra propuesta de que el mejor candidato para la $\mathrm{AD}$ sea el propio traductor del filme, así como que los actores de doblaje trabajen como narradores.

Por lo tanto, en el proceso de la $\mathrm{AD}$ — como en cualquiera destinado a colectivos minoritarios - las dificultades, y probablemente más las de tipo legislativo y financiero, no son pocas. Pero tampoco escasean los incentivos ni los estímulos, como fue la designación del pasado 2003 como año europeo de las personas con discapacidades. De hecho, no faltan buenos antecedentes en la integración audiovisual para minorías: la subtitulación para sordos es un buen ejemplo a seguir. Estamos seguros de que los diez primeros años de esta experiencia intersemiótica española impulsada por la ONCE darán paso a un período de creciente integración audiovisual. 


\section{REFERENCIAS BIBLIOGRÁFICAS}

A.A.V.V. (1994). «Un nuevo sistema permite disfrutar del teatro a ciegos y sordos». El Mundo 05/11/1994, 60.

— (2003). «El cine español exige unánimemente igualdad de condiciones para competir en su propio mercado». Academia. Boletín del cine español 88, 6-12. http://www.sie.es/acacine/boletin.htm.

- (2004). «Datos cinematográficos del mercado español». Academia. Boletín del cine español 97, 10-13.

http://www.sie.es/acacine/boletin.htm.

Agost Canós, R.; F. Chaume Varela y A. Hurtado Albir (1999). «La traducción audiovisual». En Enseñar a traducir: metodología en la formación de traductores e intérpretes, A. Hurtado Albir (ed.), 182-195. Madrid: Edelsa.

Bastos Duarte, E. (2001). «Reflexiones sobre el texto televisivo». Signa. Revista de la Asociación Española de Semiótica 10, 149-163

Bravo Gozalo, J. M. (2002). «Translating the film dialect of Hollywood for dubbing».

En Nuevas perspectivas de los estudios de traducción, J. M. Bravo Gozalo (ed.), 187-213. Valladolid: Universidad de Valladolid.

- (2003). «La investigación en traducción audiovisual en España». En Panorama actual de la investigación e interpretación (vol. 2), M. A. García Peinado \& E. Ortega Arjonilla (dirs.), 235-252. Granada: Atrio.

CEJudo, M. (1991). «Museo tiflológico y sonocine, dos proyectos de la O.N.C.E», Integración. Revista sobre ceguera y deficiencia visual 5, 26-28.

Chaume VAREla, F. (2002). «Nuevas líneas de investigación en la traducción audiovisual». En Nuevas perspectivas de los estudios de traducción, J. M. Bravo Gozalo (ed.), 215-224. Valladolid: Universidad de Valladolid.

CLARK, J. (2001). «Standard techniques in audio description». http://joeclark.org/access/description/ad-principles.html.

Delabastita, D. (1989). «Translation and mass-communication: film and TV translation as evidence of cultural dynamics». Babel 35-4, 193-218.

EYPD (European Year of People with Disabilities) (2003). http://www.eypd2003.org/eypd/index.jsp.

Galisteo, J. R. (1994). «Cine para ciegos». El Mundo. Comunicación, 6-211, 5. 
García Mateache, J. M. (2003). «¿Vemos una 'peli’ el sábado por la noche?». Así somos $9,12-13$.

García TEMPlado, J. (1997). «La homología estructural en las adaptaciones cinematográficas». Signa. Revista de la Asociación Española de Semiótica 6, 259-271.

GONZÁlEZ, L. y E. IORFIDA (2002). Cine a ciegas. http://www.cineaciegas.galeon.com/index.html.

GREIMAS, A. J. y J. courtès (1982). Semiótica. Diccionario razonado de la teoría del lenguaje. Madrid: Gredos.

INAEM (Instituto Nacional de las Artes Escénicas y de la Música) (2001). http://wwwinaem.mcu.es/ractua1.htm.

ITC Guidelines on Standards for Audio Description (2000). http://www.itc.org.uk/itcpublications/codesguidance/audiodescription/index.asp.

JAKOBSON, R. (1971a). «On linguistic aspects of translation». En Selected Writings II. Word and Language, 260-266. La Haya/París: Mouton.

- (1971b). «Linguistic types of aphasia». En Selected Writings II. Word and Language, 307-333. La Haya/París: Mouton.

Linde, Z. de y N. kay (1999). The Semiotics of Subtitling. Manchester: St. Jerome.

MAYORAL, S. (1995). «Los invidentes pueden seguir las películas de cine en Canal Sur». El Mundo 06/03/1995, 63.

Mayoral Asensio, R. (2001). «Campos de estudio y trabajo en traducción audiovisual». En La traducción para el doblaje y la subtitulación, M. Duro (coord.), 19-45. Madrid: Cátedra.

Navarrete Moreno, F. J. (1997a). «Aplicación al teatro del sistema AUDESC», Integración. Revista sobre ceguera y deficiencia visual 24, 26-29.

— (1997b). «Sistema AUDESC: el arte de hablar en imágenes», Integración. Revista sobre ceguera y deficiencia visual 23, 70-75.

NúÑEZ RAMOS, R. (1995). «El ritmo en la literatura y el cine». Signa. Revista de la Asociación Española de Semiótica 4, 181-199.

Osimo, B. (2001). «Curso de traducción: traducción intersemiótica». http://www.logos.it/pls/dictionary/linguistic_resources.traduzione_es?lang=es.

RETEMIR (1999). «El fin de los susurros». II Feria del Teatro de Ciudad Rodrigo. http://www.ciudadrodrigo.net/feriateatro/feria99/ Audesc.htm. 
Silverwood, A. (1992). «Audiodescription», DAM (Disability Arts Magazine) 2-4, 10-

14. www.leeds.ac.uk/disability-studies/archiveuk/ disability \%20arts\%20mag/ winter\%201992.pdf.

SKY (2003). «Five to use BskyB's audio description technology». Disability Information, http://www1.sky.com/disability/release2.htm.

Torop, P. (1995). «Semiótica de la traducción y traducción de la semiótica». Signa. Revista de la Asociación Española de Semiótica 4, 37-44.

VILlAÉCIJA, I. (2002). «Éxito tras la proyección de la primera película en sistema Audesc». Entrevista a Ignacio Escanero, Director de Cultura y Deporte de la ONCE. http://www.festicinehuelva.com/28edicion/0114112002.html. 